\title{
A EFETIVIDADE DAS POLITICAS DE SEGURANÇA PÚBLICA NO CONTEXTO GEOGRÁFICO PARAENSE: A RELAÇÃO DO CRIME DE HOMICÍDIO COM O ESPAÇO GEOGRÁFICO NA ÁREA METROPOLITANA DE BELÉM.
}

\author{
Marcus Paulo Ruffeil RODRIGUES ${ }^{1}$
}

\section{Resumo}

O presente artigo aborda a efetividade das politicas de segurança pública no contexto geográfico paraense delimitado na relação do crime de homicídio com o espaço urbano na área metropolitana de Belém. Objetiva-se analisar a interferência do contexto geográfico urbano na produção de crimes de homicídio. O percurso metodológico é descrito pela abordagem qualitativa, por meio da técnica da pesquisa bibliográfica e documental. Verifica-se que a complexidade do contexto geográfico do espaço urbano da área metropolitana de Belém limita o atendimento das demandas da população relativa a segurança pública, descrito por espaços geográficos de difícil acesso, elevado custo operacional, baixo nível socioeconômico, os quais contribuem direta e indiretamente na produção de crimes de homicídio. Conclui-se que a efetividade das politicas de segurança pública, delimitada na análise da relação dos crimes de homicídio com o espaço urbano produtor da vida material, interfere na construção do índice na área metropolitana de Belém.

Palavras-chave: Segurança Pública. Contexto Geográfico.Estado.

\begin{abstract}
This article discusses the effectiveness of public security policies in the geographical context of Pará delimited in the relation between the crime of homicide and the urban space in the metropolitan area of Belém. The objective is to analyze the interference of the urban geographic context in the production of homicide crimes. The methodological course is described by the qualitative approach, through the technique of bibliographical and documentary research. It is verified that the complexity of the geographic context of the urban space of the metropolitan area of Belém limits the attendance of the demands of the population related to public security, described by geographic spaces of difficult access, high operational cost, low socioeconomic level, which contribute directly and indirectly in the production of homicide crimes. It is concluded that the effectiveness of the public security policies, delimited in the analysis of the relation of the crimes of homicide with the urban space producing material life, interferes in the construction of the index in the metropolitan area of Belém.
\end{abstract}

Keywords: Public Security. Geographical Context. state

\section{INTRODUÇÃO}

O Estado do Pará expressa um contexto geográfico complexo decorrente da singularidade geográfica representada por bacias hidrográficas, florestas, áreas litorâneas, que abrigam populações de diferentes níveis sócio culturais. Tal configuração geográfica desafia a operacionalidade das politicas públicas visando responder as demandas sociais.

\footnotetext{
${ }^{1}$ Escola Brasileira de Administração Pública e Empresas (EBAP/FVG/RJ). E-mail: mprr@globo.com 
Ainda que o Estado se organize administrativamente por meio de Regiões de Integração, com o intuito de promover a descentralização da ação estatal, visando assegurar maior celeridade na operacionalização das politicas públicas, o contexto geográfico merece ser levado em consideração quanto as possíveis limitações na efetividade das politicas de segurança pública.

A expansão da fronteira territorial amazônica decorrente da implantação de empreendimentos econômicos em municípios dotados de potenciais naturais e de biodiversidade pressionou o Estado a assegurar o aparato administrativo e judiciário visando assegurar as condições objetivas de reprodução do modo de produção capitalista.

Apesar da configuração geográfica apontar mudanças significativas nos municípios que abrigam projetos econômicos, por meio de novas feições no ordenamento espacial, no entanto, essa transformação se faz acompanhar da produção de cinturões de miséria e pobreza nas áreas periféricas da sede do município.

Por outro lado, regiões que dispõem de baixos potenciais explorados economicamente, fragilidade de poder econômico e político, se ressentem da presença do aparato administrativo e judiciário estatal, revelam também vulnerabilidade nas ações de proteção social oriundas do aparelho repressivo do Estado.

A complexidade geográfica descrita no território paraense produz realidades diferenciadas no âmbito econômico, político e social, com reflexos na efetividade das politicas de segurança pública destinada ao atendimento das demandas populacionais.

Em particular na área metropolitana de Belém a configuração do contexto geográfico é produzida de acordo com as perspectivas econômicas que determinam a ocupação espacial com reflexos significativos na construção dos índices de homicídios.

O estudo da relação dos índices de crime de homicídios com o espaço geográfico na área metropolitana de Belém é pertinente ser discutido no intuito de contribuir para a produção de referenciais capazes de subsidiar as politicas de segurança pública. O percurso metodológico consta de revisão de literatura, complementado por pesquisa em fontes documentais institucionais.

No primeiro momento descreve-se a configuração espacial do Estado do Pará sob a lógica acumulativa e no segundo momento analisa-se as contradições descritas no espaço 
geográfico da área metropolitana de Belém e sua relação com os índices de crimes de homicídio.

\section{A CONFIGURAÇÃO ESPACIAL PARAENSE SOB A LÓGICA ACUMULATIVA}

O Estado do Pará é a segunda maior unidade federativa do Brasil, e insere-se num significativo espaço geográfico e territorial, caracterizado por condições socioculturais e ambientais heterogêneas no contexto de seus $1.247 .954,32 \mathrm{~km}^{2}$. Situado na região amazônica, ocupa o equivalente a $14,65 \%$ do território nacional, caracterizado por biodiversidade singular que abriga uma população de aproximadamente 7.581.051 habitantes (BRASIL, 2015).

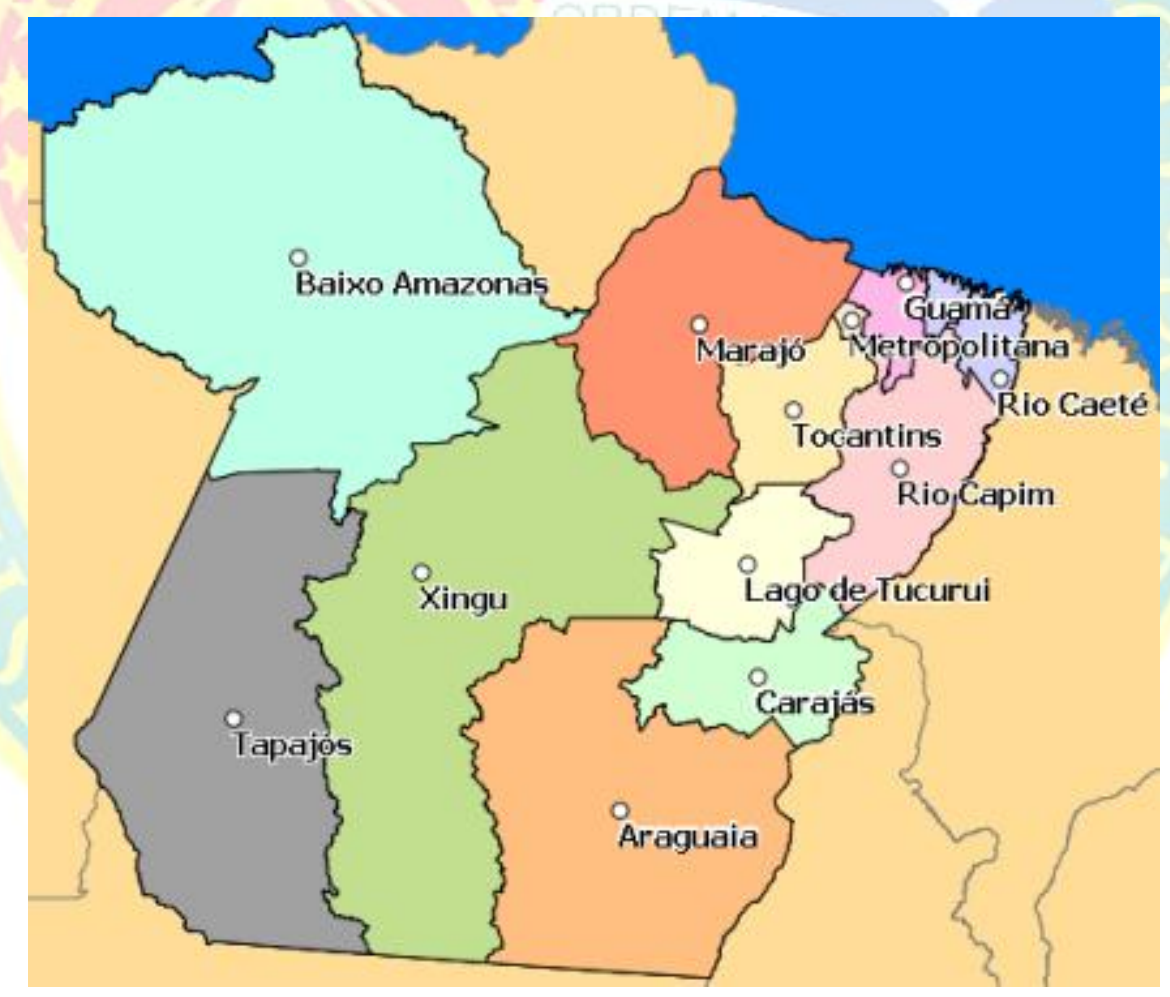

Figura 01: Configuração regional do Estado do Pará Fonte: IOEPA-2016

O Decreto $\mathrm{n}^{\circ} 1.066$, de 19 de junho de 2008 que dispõe sobre a regionalização do Estado do Pará, tem por objetivo definir regiões que possam representar espaços com semelhanças de ocupação, de nível social e de dinamismo econômico e cujos municípios mantenham integração entre si, quer física quer economicamente, com a finalidade de definir Revista do Instituto Histórico e Geográfico do Pará (IHGP), (ISSN: 2359-0831 - on line), Belém, v. 05, n. 01, p. 01-12, jan./jun. 2018. 
espaços que possam se integrar de forma a serem partícipes do processo de diminuição das desigualdades regionais (PARÁ, 2008).

O cenário político no Estado do Pará na última década do século XX e início do século XXI vêm experimentando um projeto de poder concentrado nas elites conservadoras que se alternam no controle do aparato administrativo estatal, com reflexos acentuados na definição das políticas sociais, orientadas segundo a lógica ditada pelos organismos internacionais visando expandir a fronteira do capital na região amazônica.

A presença do capital na região amazônica, em especial no Estado do Pará, assumiu proporção significativa nas atividades econômicas, a partir das décadas de 1980 e 1990 com a implantação dos grandes projetos econômicos, mediante a exploração de recursos naturais, que possibilitou a formação de novos espaços territoriais, e, consequentemente, o surgimento de novas perspectivas de embates no campo político, representado por grupos conservadores e progressistas (SANTOS, 2014).

Esse cenário produziu mudanças relevantes no espaço geográfico paraense, descrito a partir da transformação de vilas e localidades em municípios, principalmente em decorrência da exploração econômica de recursos naturais. Tais mudanças ocorreram em meio a limitações de equipamentos públicos e a capacidade da gestão municipal no atendimento das demandas populares.

\footnotetext{
Assim, a urbanização caminha para um descompasso entre o número de pessoas que chegam do campo e a oferta de emprego disponíveis e nesse sentido o Brasil começa a sofrer um inchaço populacional em suas metrópoles e inicia-se uma série de problemas relacionados à questão urbana como, favelização, marginalização, desemprego, informalidade e segregação (COUTO, 2013, p. 42).
}

As transformações do contexto geográfico paraense imprimiram novos desafios ao Estado, especialmente quanto a implantação dos equipamentos públicos, tais como: escolas, unidades de saúde, delegacias de policia, defensorias públicas, e outros.

Os grupos econômicos instalados no território paraense, não fogem à regra nos modus operandis na construção da relação com o Estado, pois necessitam estar representados na estrutura político-administrativa, visando a defesa de seus interesses. De acordo com Marx (2009), o Estado é a síntese do processo de dominação resultante da divisão da sociedade em classes, portanto está inserido no contexto dos antagonismos de classes. Diz o autor que, 
Como o Estado é a forma em que os indivíduos de uma classe dominante fazem valer os seus interesses comuns e se condensa toda a sociedade civil de uma época, segue-se que todas as instituições comuns que adquirem uma forma política são mediadas pelo Estado (MARX; ENGELS, 2009, p. 112).

A articulação dos grupos econômicos com o Estado desdobra-se no âmbito da sociedade civil por meio de entidades representativas, com participação efetiva no processo produtivo, as quais desempenham um papel relevante no controle político e na difusão do discurso ideológico do bem-estar pela via do capital privado. A configuração do Estado na unidade federativa paraense não foge a essa regra, descrito por contrastes elevados quanto ao controle dos meios de produção, restrito a um grupo limitado de sujeitos, com reflexos significativos na produção existencial do povo.

A expansão das atividades produtivas no espaço geográfico paraense definiu novas estratégias de alianças entre os grupos políticos, com a finalidade de assegurar o controle administrativo do Estado e também, ampliar o desenvolvimento econômico por meio de dispositivos legais, visando promover a sustentabilidade dos grupos empresariais. A relação do Capital com o Estado desenhou-se no contexto geográfico paraense, por meio da manutenção do modelo reprodutor de desigualdade social.

Se em todas as épocas a estabilidade do poder público significava tudo para todo o mercado financeiro e para os oficiantes desse mercado financeiro, por que não o seria hoje, e com muito mais razão, quando cada dilúvio ameaça destruir os velhos Estados e, com eles, as velhas dívidas do Estado? (MARX, 1981, p. 73).

As bases produtivas existentes no Estado do Pará estão alicerçadas fundamentalmente na atividade de comércio e serviços, agronegócio, indústria, e, politicamente, esses segmentos se fazem representar por entidades de classe com articulação dentro da estrutura administrativa e política do Estado, por meio da Federação do Comércio - FECOMÉRCIO; Federação da Agricultura do Pará - FEAPA; Federação das Indústrias do Pará - FIEPA (SANTOS, 2014).

A presença da elite econômica no controle dos meios de produção e da administração do Estado limita a ação dos movimentos sociais na transformação das condições materiais de desigualdade construídas historicamente no Estado do Pará, os quais contribuem para a manutenção da elevada concentração de renda, restrito a pequenos grupos sociais. 
Nesse contexto, a limitação da politica de proteção social à população decorre da complexidade da configuração geográfica do território paraense, especialmente nos espaços de difícil acesso, em que o poder local não expressa relevância na constituição do poder politico global.

Os grupos econômicos se instalam em territórios dotados de potenciais naturais a serem explorados economicamente e em paralelo assumem o controle político, visando resguardar seus interesses. Dessa forma, reproduz-se a lógica da hegemonia do poder econômico e poder político no âmbito do Estado.

A presença dos grupos econômicos no controle do Estado reflete de forma considerável na definição e operacionalização das políticas sociais, por meio da substituição do papel do Estado como protagonista das ações, ocupando tal espaço, a iniciativa privada por meio de institutos, fundações, e demais organizações vinculadas ao Terceiro Setor. Essa mudança de atuação do Estado junto à sociedade possibilita construir uma estratégia de visibilidade ao empresariado junto a população, como protagonista eficaz no atendimento das demandas sociais.

Segundo Couto (2013) a presença de estruturas produtivas nos diversos contextos geográficos do Estado do Pará, não produz transformação social, ao contrário, ampliam-se espaços de pobreza e miséria. Além disso, o Estado em algumas situações é representado em sua estrutura administrativa e politica, somente por escolas públicas ou unidades de saúde em parceria com a administração pública municipal.

Essa nova lógica de funcionamento estatal fortalece, no imaginário social, o discurso da fragilidade estatal no atendimento das demandas sociais, as quais, podem atingir níveis de qualidade satisfatória, quando operacionalizados por instâncias não-estatais, que supostamente seriam mais eficientes e eficazes no cumprimento do papel a que se destinam.

O capital ao assumir o controle político do Estado, concentra as atividades produtivas e da renda em torno de uma minoria, com reflexos significativos na estrutura social, devido à elevação da desigualdade quanto ao acesso aos meios de produção da existência humana, com ressonância significativa no atendimento das demandas sociais. 


\section{AS CONTRADIÇÕES GEOGRÁFICAS DESCRITAS NO ESPAÇO URBANO DA ÁREA METROPOLITANA DE BELÉM E SUA RELAÇÃO COM OS ÍNDICES DE CRIMES DE HOMICÍDIO}

A descrição do espaço urbano da área metropolitana de Belém expressa contornos resultantes das atividades econômicas historicamente produzidas, dispostas na contradição riqueza-pobreza, ditadas de acordo com a organização politica determinada a partir da lógica estabelecida pelo Estado.

As relações de poder estabelecidas na sociedade paraense, em particular, na área metropolitana de Belém, produziu espaços urbanos diferenciados referendados por valores econômicos, em que as classes economicamente abastadas situam-se nas áreas dotadas de infraestrutura e equipamentos públicos voltados ao atendimento de demandas. Em sentido oposto, os segmentos sociais hipossuficientes economicamente, ocupam espaços com limitações de infraestrutura e equipamentos públicos.

Nessa perspectiva o espaço é política, na medida em que não é apenas suporte ou projeção da politica e da vida material e cultural. Como produto da ação da vontade humana, da relação entre os homens, o espaço é a própria expressão da política e de tudo aquilo que ela implica - signos, representações, ideologias e tensões. O espaço também é politica, na medida em que é parte integrante de uma esfera pública, meio e mediação da vida social (OLIVEIRA, 2013, p. 117).

A produção do espaço orientado segundo as relações de poder determina também perspectivas de materialização das politicas sociais, dentre estas, a saúde, educação, segurança pública, cultura e lazer, e outras demandas fundamentais a promoção da qualidade de vida.

A dicotomia centro/periferia é produzida a partir das relações de poder construídas por sujeitos concretos referenciados a partir do controle dos meios de produção. O aspecto econômico impõe também a disposição dos equipamentos públicos, oriundos das politicas de Estado.

O centro e, por conseguinte, sua valorização faz parte da retórica da urbanização das cidades brasileiras. No caso de Belém, este processo se deu de forma enfática, tanto no aspecto da concentração dos equipamentos urbanos, como na aglutinação da população de elevado padrão de vida em bairros considerados centrais da cidade (OLIVEIRA; SILVA, 2013, p. 105).

Nesse contexto, a ocupação do espaço urbano na área metropolitana de Belém desenhou-se em função da disposição geomorfológica, em que as áreas de terra firma foram 
ocupadas por estratos sociais economicamente abastados e as áreas sujeitas a inundações, constituíram-se em espaços destinados a construção de habitações para as populações pobres.

As áreas periféricas da área metropolitana de Belém habitada por estratos sociais hipossuficientes economicamente, revelam um quadro adverso no atendimento das politicas sociais, e consequentemente mais vulneráveis para a ocorrência de delitos.

O processo de ocupação das baixadas do centro, contribuiu para intensificar o surgimento de periferias caracterizadas a partir da construção de casas em palafitas, localizadas as margens de igarapés e rios, passagens sobre estivas, bem como a vida humilde e cheia de dificuldades passadas por seus habitantes (SANTOS;PIMENTEL, 2013, p. 181).

As limitações de ordem econômica e do atendimento das demandas sociais oriundas das politicas governamentais, dentre estas a saúde, educação, acesso ao judiciário, segurança pública, saneamento básico, agua tratada, contribuem de forma direta para práticas de ilegalidade.

A cobertura do policiamento ostensivo integrante da politica de segurança pública nos bairros periféricos da área metropolitana de Belém revela complexidade decorrente das barreiras produzidas no desordenamento do espaço urbano e obstáculos naturais, oriundos da falta de infraestrutura de saneamento básico, asfaltamento de vias públicas, falta de mobilidade decorrente de áreas inundadas e cuja única via de acesso ocorre sobre estivas.

De acordo com Brandão (2010) o homem torna-se tal mediado pelo contexto sócio cultural, de modo que as condições espaciais destinadas à promoção da vida material, especialmente nos bairros periféricos, destituídos em sua maioria de equipamentos públicos e infraestrutura básica para a promoção da dignidade humana, pode contribuir de forma direta na constituição dos sujeitos.

Os bairros periféricos da área metropolitana de Belém, abrigam em sua maioria a população com baixa escolarização, níveis de qualificação destinados a ocupações de postos de trabalho em funções subalterna, alguns em atividades no mercado de trabalho informal, o que projeta situações de instabilidade no vínculo empregatício.

Segundo os dados estatísticos da Secretaria de Segurança Pública do Pará, o número de homicídios na Região Metropolitana de Belém expressa valores acentuados, os quais 
ocorrem em sua maioria em áreas periféricas onde se localizam a maioria das instituições policiais destinadas ao registro de ocorrências.

\begin{tabular}{c|c|c}
\hline ANO & HOMICIDIOS & ICHomX100 mil hab \\
\hline 2010 & 1.490 & 73,01 \\
\hline 2011 & 1.033 & 50,11 \\
\hline 2012 & 1.043 & 50,15 \\
\hline 2013 & 1.140 & 53,97 \\
\hline
\end{tabular}

O aparato repressivo do Estado representado por unidades policiais visando promover a politica de segurança pública na área metropolitana de Belém é disposto em sua maioria em espaços periféricos, e consequentemente os registros dos índices de homicídios ocorrem nesses espaços. Para Chagas (2013) o território é um espaço de representação do poder, e a instalação de unidades policiais nos bairros periféricos é estrategicamente definida visando o controle social.

A quantidade de homicídios registrados na área metropolitana de Belém, em sua maioria nos espaços periféricos, evidencia fragilidade no processo de desenvolvimento regional resultante da reprodução da miséria e pobreza da ação do capital.

A organização dos aparelhos repressivos movimenta-se conforme o fluxo descrito nas relações de poder, e no caso das unidades policiais é possível identificar o quanto o Estado define os territórios possíveis de se estabelecer a ação coercitiva, visando assegurar a ordem e o controle das ações humanas. 


\begin{tabular}{|c|c|}
\hline Unidades Policiais & Bairro \\
\hline $1^{\text {a }}$ Seccional urbana & Sacramenta \\
\hline $2^{\mathrm{a}}$ seccional urbana & São Braz \\
\hline Delegacia de Polícia do Marco & Marco \\
\hline $3^{\circ}$ seccional urbana & Coqueiro \\
\hline $4^{\text {a }}$ seccional urbana & Cremação \\
\hline Delegacia de Polícia do Jurunas & Jurunas \\
\hline $5^{\text {a }}$ seccional urbana & Marambaia \\
\hline Delegacia de Policia do Atalaia & Atalaia \\
\hline Delegacia de Policia do Bengui & Benguí \\
\hline Delegacia de Polícia da Cabanagem & Cabanagem \\
\hline Delegacia de polícia da Guanabara & Guanabara \\
\hline Delegacia de Polícia da Jaderlandia & Jaderlandia \\
\hline $6^{a}$ seccional urbana & Comercio \\
\hline 7 seccional urbana & Curucambá \\
\hline 8 seccional urbana & Icoaraci \\
\hline Delegacia de policia de outeiro & Outeiro \\
\hline 9 seccional urbana & Mosqueiro \\
\hline 10 seccional urbana & Pedreira \\
\hline 11 seccional urbana & Guamá \\
\hline Delegacia de policia da Terra Firme & Terra Firme \\
\hline 14 seccional urbana & Ananindeua \\
\hline Delegacia de policia do Aurá & Ananindeua \\
\hline Delegacia de policia do Julia Sefer & Aguas lindas \\
\hline
\end{tabular}

\section{Fonte:SEGUP/PA}

A presença de unidades policiais nos espaços periféricos da área metropolitana de Belém implica no controle da ação das massas, ao mesmo tempo em que possibilita reunir elementos fundamentais para a articulação das politicas de segurança pública, com o objetivo de tornar mais eficaz a ação do Estado.

Ainda que as unidades policiais estejam localizadas em espaços periféricos na área metropolitana de Belém, a ação operacional visando a prevenção do crime de homicídio é ineficaz decorrente das limitações de infraestrutura existentes nos diversos bairros, que impede a realização de ações preventivas. 


\section{CONSIDERAÇÕES FINAIS}

O estudo relativo a efetividade das politicas de segurança pública no contexto geográfico paraense delimitado na relação do crime de homicídio com o espaço geográfico na área metropolitana de Belém, possibilita apontar alguns elementos relevantes para a construção de estratégias voltadas a subsidiar o planejamento articulado das politicas sociais.

A análise do contexto geográfico é de fundamental importância na definição de estratégias voltadas a ação preventiva do crime de homicídio, considerando a incidência em maiores proporções nos bairros periféricos da área metropolitana de Belém.

As limitações de infraestrutura nos bairros periféricos é um dos fatores que necessitam ser levados em consideração nas politicas de segurança pública, visando promover a redução dos índices de homicídio. A ocupação dos espaços geográficos periféricos em sua maioria por sujeitos hipossuficientes de recursos econômicos, complementado pela fragilidade da oferta de educação, saúde, agua tratada, mobilidade, reproduzem um quadro indigente propício a práticas ilegais.

O Estado ao dispor os aparelhos repressivos em espaços periféricos, objetiva estabelecer o controle das massas, no entanto, tal estratégia não se faz acompanhar do atendimento de outras demandas sociais. A incidência de crimes de homicídios na área metropolitana de Belém pode ser um indicador do descompasso do processo de reprodução da lógica acumulativa.

\section{REFERÊNCIAS}

BRANDÃO, Carlos Rodrigues. O que é educação? São Paulo: Brasiliense, 2010.

BRASIL. Instituto Brasileiro de Geografia e Estatística. Rio de Janeiro, 2015.

CHAGAS, Clay Anderson Nunes. Tendências recentes de desenvolvimento regional e gestão do território. Sociedade,Espaço,Políticas Territoriais na Amazônia Paraense. Belém: GAPTA/UFPA, 2013.

COUTO, Aiala Colares. A Amazônia e o pensamento desenvolvimentista para a região: do desenvolvimento global ao desenvolvimento local sustentável. Sociedade,Espaço,Políticas Territoriais na Amazônia Paraense. Belém: GAPTA/UFPA, 2013.

IOEPA. Imprensa Oficial do Estado do Pará. Belém, 2016. 
MARK, Karl; ENGELS, Friedrich. A Ideologia Alemã. São Paulo: Expressão Popular, 2009.

MARK, Karl. O 18 do Brumário de Bonaparte. São Paulo: Bomtempo, 1981.

OLIVEIRA, Janete Marília Gentil Coimbra de. Espaço, natureza e sociedade. Olhares e perspectivas. Belém: GAPTA/UFPA, 2013.

OLIVEIRA, Janete Marília Gentil Coimbra; SILVA, Carlos Alberto da. Espaço e Sociedade. Belém, GAPTA/UFPA, 2013.

PARÁ. Secretaria de Estado de Segurança Pública do Pará - SEGUP/PA. Belém, 2011.

SANTOS, Milton. Por uma outra globalização. Rio de Janeiro. Editora Record, 2004.

SANTOS, Terezinha Fátima Andrade Monteiro dos. Educação e desenvolvimento: que relação é essa? Belo Horizonte: Revista Trabalho \& Educação. v.23 | n.1 | p. 219-238 | jan/abr | 2014

SANTOS, Carlos Jorge Paixão; PIMENTEL, Rúbia. O desenvolvimento da Amazônia em debate. Belém: CEJUP, 2013. 